\title{
REPERTORIUM VAN TIJDSCHRIFTLITERATUUR OP HET GEBIED VAN ACCOUNTANCY EN BEDRIJFSHUISHOUDKUNDE
}

april 1970

Verschijnt maandelijks, behalve in augustus. Samengesteld door de Stichting voor ticono misch Onderzoek der Universiteit van Am sterdam

\section{A. ACCOUNTANCY}

\section{L.EER VAN DE ADMINISTRATIEVE ORCIANISATIE}

De betekenis van de adviesfunktie van de accountant met betrekking tot automatisering van de administratieve organisatie met behulp van computers

Van Sijtveld, $H$. - De laatste jaren is het aantal computers snel gestegen en de verwachting lijkt gewettigd dat deze stijging zich in de komende jaren nog in versterktc mate zal voortzetten. Er is ook cen kwalitatieve verandering te bespeuren in dic zin, dat de computer meer in de beleidssfeer wordt toegcpast.

Voor de accountant is deze ontwikkeling van groot belang, omdat $\pm 80 \%$ van de toepassingen op het terrein van de administratieve organisatie ligt. Zowel in zijn kontrolerende als in zijn adviserende functie komt hij voortdurend in kontakt met computers. Als kontroleur wordt hij gekonfronteerd met geautomatiseerde administraties welke hij moet kontroleren. In zijn hoedanigheid van adviseur wordt hij geacht cen keuze te maken uit dé bestaande systemen in de voor het bedrijf meest geschikte configuratie.

Voorts dient de accountant de invloed na te gaan welke de invoering heeft op de praktische gang van zaken in de administratieve organisatic.

In dit artikel wordt vooral het zwaartepunt gelegd op deze adviserende taak van de accountant. Hem kan een oordeel worden gevraagd over de volgende aspekten: is het bedrijf rijp voor een computer? welke onderdelen van de administratie komen in aanmerking voor automatische verwerking? dient het systecm drastisch of geleidelijk te worden ingevoerd? is de aanschaf van een computer uit kosten. oogpunt verantwoord? De accountant moet zich als computer-adviseur echter niet begewen op het terrein van de definitieve selectie. Hij mag wel een voorkeur uitspreken op grond van objectieve, meetbare factoren en met bijstand van deskundigen, maar moet de uiteindelijke keuze aan de opdrachtgever laten. Ook bij de invoering van het systeem is hij (en zijn medewerkers) niet op zijn plaats. Op de gevaren van zijn medewcrking aan de realisatie van het computcrproject wordt gewezen.

A III-3

Informatie, september 1969

E 642.332 .23

\section{B. BEDRIJFSHUISHOUDKUNDE}

\section{a. ALGEMENE BEDRIJFSHUISHOUDKUNDE}

\section{II. WAARNEMINGSMIDDELEN}

\section{Modern presentation of information in balance sheets and accounts for shareholders}

Richards, D. G. - Bij de opstelling van een jaarverslag is het nuttig een onderscheid te maken tussen twec kategorieèn aandechouders, de partikulicre en de institutionele beleggers. De eerste hebben voldoende aan cen eenvoudig overzicht van de belangrijkste jaarcijfers ter bepaling van solvabiliteit en rentabiliteit. De tweede grocp wenst beduidend meer informatie.

Voor de onderneming is het van belang beide groepen tevreden te stellen. Zij kan dit verwezenlijken door in het begin van het verslag op overzichtelijke wijze de belangrijkste cijfers en prognoses op te nemen. In het laatste gedeelte komen dan de toelichtingen, verhoudingscijfers e.d. voor de meer deskundige lezer. In verband hiermee wordt een inhoud van het jaarverslag voorgesteld in de volgorde: verslag directie, verslag accountant, geconsolidecrde winst. en verliesrekening en balans, toelichting hierop, verdere statistische gegevens in de vorm van tabellen, kaarten, grafieken e.d. Op de gewenste vorm en inhoud van deze onderdelen wordt afzonderlijk ingegaan. Daarbij wordt aangegeven 
welke posten de balans en de winst- en verliesrekening minimaal moeten bevatten voor een goede en begrijpelijke informatie aan alle aandeelhouders. In de toelichting moeten details worden opgenomen, die voor de institutionelc beleggers van belang zijn voor de beoordeling van de rentabiliteit, rekening houdend met de inflatie van hun belegging. Twee belangrijke gegevens daarvoor zijn: de wijze van afschrijving en de vergelijkbaarheid van de waarde van de vaste activa i.v.m. de verschillende tijdstippen van aanschaf. Voor een juiste beoordeling van de rentabiliteit van het geinvesteerde vermogen zouden de vaste aktiva om de paar jaar opnieuw moeten worden gewaardeerd op basis van een algemene prijsindex. Tenslotte worden een aantal financiële gegevens genoemd die in een statistisch overzicht over de laatste tien jaar zouden moeten worden opgenomen om het beeld van de onderneming te completeren.

In het algemeen bevordert een overzichtelijke presentatie van de gegevens met behulp van kaarten grafieken en andere hulpmiddelen ten zeerste de kommunikatie met de aandeelhouders.

13a $111-5$

E 771

The Accountant, 20 november 1969

\section{Toerekening van reklame-kosten}

\section{L.FFR VAN DE KOSTPRIJS EN DE PRIJSVORMING}

Janzing, Drs. G. B. M. - In dit artikel worden de mogelijkheden onderzocht om de reklamekosten rationeel aan de produkten toe te rekenen ingeval een onderneming meer produkten op de markt brengt. Gewoonlijk wordt een onderscheid gemaakt tussen direkte en indirekte reklamckosten. Dit is van belang voor de verdeling van deze kosten. Bij toerekening aan een bepaalde periode doet zich het probleem voor dat er geen duidelijke samenhang bestaat tussen de reklameaktiviteiten en de verkopen in hetzelfde tijdvak. Soms heeft de reklame geen effect. Zij moet dan als verspilling ten laste van het resultaat van de betreffende periode worden gebracht. De overige kosten kan men aktiveren en hierop wordt afgeschreven in verhouding met de omzet. Hiertoe kan men zowel van de werkelijke als van de geraamde omzet uitgaan. Deze periodenbegrenzing is vooral van helang voor de resultatenherekening op korte termijn. In de regel zal het niet gedekte restant als verlies moeten worden beschouwd.

Als men de reklamekosten aan de produkten wil toerekenen, is het gewenst een onderscheid te maken tussen reklame voor één artikel of voor meer artikelen. In het laatste geval is er de moeilijkheid van wederzijdse beinvloeding. Bij de kostenverdeling dient men rekening te houden met verschillende mogclijkheden: reklame voor twee of meer niet konkurrerende, elkaar vervangende, of elkaar aanvullende artikelen of merkreklame voor alle produkten. Verder noemt de schrijver enige verdeelsleutels die in dit verband kunnen worden toegepast. In de praktijk wordt eenvoudigheidshalve de marktwaardemethode gebruikt. Deze geeft een verdeling van de kosten naar de omzet. Volgens de schrijver werkt deze methode soms wel bevredigend, mits aan bepaalde voorwaarden is voldaan.

De vaste kosten van de reklameafdeling, welke afhankelijk zijn van de gewenste beschikbaarheidsnuttigheid moeten aan de individuele produkten worden toegerekend op basis van de op lange termijn begrote reklame, de variabele kosten daarentegen overeenkomstig de feitelijk gemaakte reklame.

De schrijver komt tot de konklusie dat een in alle opzichten bevredigende verdeling van de reklamekosten een onbereikbaar idcaal is. Vooral met het oog op tussentijdse resultatenoverzichten is een bcpaalde toerekening echter toch onmisbaar.

Ba IV-2a

Synopsis, januari/februari 1970

E 136.351 .2

\section{Statistical Cost Allocation}

McRae, T. W. Hoewel de steekproeftheorie door accountants en administrateurs nog niet vaak wordt gebruikt, zijn er niettemin enige terreinen waar toepassing van groot nut kan zijn, vooral als de gewenste extra informatie niet kan worden verkregen uit andere bronnen. Een voorbeeld van zo'n toepassingsgebied is volgens de schrijver de berekening van de direkte kosten per afdeling, omdat dan vaak is voldaan aan enige voor de toepassing van de stcekproeftheorie noodzakelijke voorwaarden: (a) de te verdelen hoeveelheid elementen is relatief groot (b) geen der elementen heeft een uitzonderlijk hoge waarde (c) volstrekte nauwkeurigheid is niet vereist en (d) conventionele methoden zijn te omslachtig of tc kostbaar. In het kort worden behandeld: het verzamelen van de gegevens, het trekken van de steekproef, en het kiezen van de gewenste nauwkeurigheid en betrouwbaarheid. Aan de hand van 3 praktijkvoorbeelden laat de schrijuer zien dat men kosten, die vroeger niet verdecld konden worden, nu met weinig mocite wel toerekent waardoor beter inzicht in de efficiency van de verschillende afd.lingen ontstaat. 


\section{V1. LEER VAN DE ORGANISATIE}

The product life cycle as an aid in strategy decisions

Scheuing, Dr. E. E. - De levenscyclus van een produkt is een gegeneraliseerd model van de afzetkurve. Hicrin worden verschillende fasen onderscheiden. De tijdens deze stadia optredende veranderingen worden beschreven aan de hand van de volgende kenmerken: type koper en verkoper, marktvorm, prijselasticiteit van de vraag en veranderingen in de produktie en de marketing.

Teneinde de beste strategie te kunnen bepalen is het voor de bedrijfsleiding van groot belang te weten op welk punt van de levenscyclus het produkt zich bevindt. Dit is mogelijk door vergelijking van de afzetkurve, de verlies en winstkurve en de marginale afzetkurve.

Het blijkt dat in de diverse stadia van de levenscyclus een gedifferentieerde politiek moet worden gevolgd met betrekking tot de prijs, de keuze van de afzetkanalen, de wijze van reklame maken en de mate van produktdifferentiatie. Zo zal in de eerste jaren na de introduktie de prijs vaak sterk dalen. Dit wordt geillustreerd met enige grafieken van het prijsverloop van farmaceutische produkten. De schrijver onderscheidt na het eerste verzadigingspunt vier mogelijke alternatieven: vermindering, stabiliteit, verdere groci en uitbreiding van de verkoopactiviteiten. Deze mogelijkheden worden toegelicht met een grafiek.

Om de omzetdaling in het verzadigingsstadium tegen te gaan zijn twee remedies denkbaar. Het substitueren van het bestaande produkt door nieuwe produkten of variëteiten; dit gaat gepaard met hoge kosten van ontwikkeling omdat slechts een klein gedeelte van de ideeën tot suksesvolle produkten leidt. Een andere oplossing is het uitbreiden van de bestaande markt door stimulering van het gebruik door bestaande kopers en door niet-kopers aan de ene kant en het zoeken naar nieuwe tocpassingen aan de andere kant.

Ba VI-12

Management International Review, 19694.5

E 641.254

\section{Een- of meerh oofdige leiding?}

Van Maanen, R. - De vraag inzake één- of meerhoofdige leiding relateert de schrijver aan de begrippen 'leiden' en 'besluiten'. T.a.v. besluiten onderscheidt hij drie verschillende aspecten: besluitconcipiëring, besluitbepaling en besluituitvoering. De besluitconcipiëring moet meerhoofdig zijn, wanneer de verantwoordelijke leiding niet in staat is een oordeel te vormen over de betekenis van dc faktoren dic een beslissende invlocd uitoefenen op het ondernemingsdoel. Dit is veelal het geval bij grotere ondernemingen.

In de uitvoeringsfase, waarin de doelstellingen worden gerealiseerd, is éénhoofdige leiding vereist. In deze fase 'dienen discussies over het doel en de aangegeven richtlijnen achterwege te blijven, noch dient het mogeiijk te zijn dat de op gang zijnde actie wordt onderbroken door een andere dan de instantic die met de uitvoering is belast'.

Het recht van besluitbepaling - het nemen van het besluit tot actie conform het voorbereidingsbesluit behoort tot de bevoegdheden van de verantwoordelijke leiding. Deze leiding kan zowel één-als meerhoofdig zijn.

De keuze tussen één- of meerhoofdige leiding moet afhankelijk zijn van de omstandigheden waarin de onderneming verkeert. Deze omstandigheden kunnen al naar gelang de groeifase waarin de onderneming zich bevindt, de personele bezetting en de histnrie van de onderneming sterk verschillen. De schrijver kcert zich hiermee tegen de opvatting dat men een keuze ten gunste van één van de beide organisaticvormen kan maken op grond van een beginsel.

Ba VI-16

E 641.22

Tijdschrift voor efficiënt directiebeleid, januari 1970

\section{Manager van overmorgen}

Eyzenga, G. R. Dit artikel is geinspireerd op de toekomstige ontwikkelingen in het Amerikaanse 
grootbedrijf, zodat de conclusies nog niet relevant zijn voor de minder grote ondernemingen. Volgens de schrijver is er een tendens waarneembaar dat de oude lijn-staf organisatie, weergegeven door een piramide geleidelijk verdwijnt en een nieuwe struktuur in de vorm van een paddestoel ontstaat. De mechanisering en later de automatisering hebben bij het 'lower management' en de uitvoering een accentverschuiving teweeggebracht van uitvoerende naar toezichthoudende arbeid. Het gevolg is een vermindering van het aantal arbeidsplaatsen in de onderste laag van de piramide, gepaard gaande met een verhoging van het in kapitaalgoederen geinvesteerde bedrag. Ook het 'middle management' dat voor een belangrijk deel uit dienstverlening bestaat, wordt geautomatiseerd en gecentraliseerd. Hierdoor ontstaat een groot overschot aan administratief personeel. Ten dele kan dit worden omgeschoold tot specialist als systeem-analist of programmeur, maar een ander deel zal op lagere niveaus moeten worden tewerk gesteld of naar andere organisaties vertrekken.

De middenmoot wordt zo tot een smalle hoge kolom, waarbinnen hoofdzakelijk specialisten werkzaam zijn. Het huidige topmanagement bestaat vaak uit slechts twee man, bijgestaan door een staf die meestal veel te weinig bij de leiding wordt betrokken. Als algemene taak van het management ziet de schrijver het handhaven op eigen kracht van de continuiteit van de onderneming.

In de geschiedenis van een bedrijf zijn vaak verschillende soorten managers te onderkennen: de promotorfiguur, de consolidator of organisator en de manager met toekomstvisie en durf. In het managementteam van de toekomst zullen de genoemde basistypen naast elkaar een plaats vinden. Er wordt een onderscheiding in deeltaken van het management gegeven overeenkomstig de indeling van Ansoff en Brandenburg. Dit wordt toegelicht aan de hand van schema's vàn de management-cyclus, de implementatie-cyclus, de controle-cyclus, de extrapolatieve cyclus en de ondernemerscyclus. Eén manager is niet in staat al deze funkties naar behoren te vervullen. Hiervoor is een team nodig waarvan de leden, al naar gelang de aard van het probleem, afwisselend de leiding nemen.

Dit impliceert dus dat gezagskriteria op funktionele basis worden vervangen door operationele kriteria. De specialisatie binnen de leiding cnerzijds en de uniformering van de opleidingseisen voor de diverse management funkties anderzijds verhogen de mobiliteit van de ondernemer.

Uitwisseling tussen bedrijven, nationaal en internationaal, wordt door de professionalisering van het management sterk bevorderd.

Ba VI-16

Intermediair, 6 februari 1970

E 641.22

\section{Cost Control for the Marketing Function}

Cheng, P. C. en Bell, J. E. - Omdat de marketing activiteiten toenemen, nemen ook de kosten hiervan toe. Een recente uitgebreide studie heeft aan het licht gebracht dat reeds meer dan $40 \%$ van de totale kusten van goederen, bestemd voor finale afzet, marketing kosten zijn. Het is daarom noodzakelijk ook op dit terrein de kosten in de hand te houden, hoewel dit moeilijker blijkt te zijn dan voor produktiekosten. De schrijvers zijn echter van mening dat de gewone boekhoudkundige gegevens, mits op de juiste wijze gesplitst en gesorteerd, voldoende zijn om de produktmanager de goede informatie te geven. Behalve informatie over het verleden, is een nauwkeurige schatting van het gedrag der verschillende kostensoorten in de toekomst van groot belang om binnen het budget te kunnen blyven. De schrijvers menen dat regressierekening hierbij nauwkeuriger werkt dan grafische extrapolatie. Een voorbeeld toont aan, dat als de gewenste vergelijkingen eenmaal m.b.v. regressie bepaald zijn, de schattingen uit te rekenen zijn. Als deze procedure bijv. tweemaandelijks herhaald wordt, krijgt de produktmanager betere informatie dan wanneer hij alleen het gebudgetteerde jaartotaal kent.

Ba VI-18

Management Accounting, februari 1970

E 641.224 .2

\section{How to manage financially}

Kingshott, L. - Tussen de V.S. van Amerika en Engeland is sprake van een 'management technology gap'. Met name geldt dit ook voor een onderdeel van de management, de financiële management.

De wijze waarop Amerikaanse ondernemingen financial management bedrijven valt te beschrijven vanuit vier gezichtspunten: 1 . de filosofie die achter Amerikaanse financiële managementtechnieken zit, 2. hoe organiseert men het verzamelen van belangrijke financiële gegevens, 3. hoe deze informatie te gebruiken, 4 . wat levert deze techniek op?

Met betrekking tot het eerste gezichtspunt gaat het erom de doeleinden van de onderneming te 
vertalen in financiele grootheden zoals bv. netto winst in procenten van de opbrengst, bydrage tor de winst van de verschillende produkten enz. Elke funktionaris moet met de voor hem relevante data werken en ze gebruiken bij het nemen van zijn beslissingen. De organisatie van de gegevensverzameling valt uiteen in de organisatie van gegevens en de organisatie van mensen. Basıs voor de gegevensverschaffing is de bockhouding, die hierop ingericht dient te zijn. Van belang is voorts de rapportering waarin confrontatie van werkelijkheid en voorspelling plaatšvindt. Nadat vastgesteld is welke gegevens verzameld dienen te worden, worden degenen aangewezen die verantwoordelijk zijn voor het produceren van financic̈lc data en wordt vervolgens bepaald aan wie dit materiaal moet worden doorgegeven.

De meeste gocd renderende Amerikaanse ondernemingen maken op vrijwel identieke wijze gebruik van de verzamelde financiele gegevens, hetgeen er op neer komt dat toepassing ervan zich tot vrijwel alle onderdelen van het bedrijf uitstrekt en dat op grondige wijze. Bovendien maakt men bij het in praktijk brengen van deze techniek een onderscheid tussen beinvloedbare en nict-beinvloedbare grootheden. Wat levert deze managementtechnick nu op? Allereerst dat aanwijzingen worden verkregen waar de zwakke plekken zijn in het bedrijfsgebeuren en hoe deze op te heffen. Verder kan men dankzij deze gegevens intern vergelijkingen maken die kunnen worden gebruikt als hulpmiddel bij het nemen van beleidsbeslissingen. Wel dient men op te passen dat zo'n verfijnd systeem gcen frustraties oprocpt bij bepaalde personen vanwege het zeer gedisciplineerde karakter van deze Amerikaanse techniek. Ruimte moet er blijven voor intuitief handelen, hoewel dit minder wordt naarmate de onderneming groeit. Navolging van deze techniek in Europese ondernemingen verdient aanbeveling zij het dat men er rekening mee moct houden dat de Europeaan een ander gevoel voor discipline heeft dan de Amerikaan. Gewaarschuwd wordt tegen teveel imitatic.

Ba V1-16

E 641.224

Management Today, februari 1970

\section{What's different about conglomerate management}

Berg, N. A. - Ten aanzien van de groei van de omzet en de winst zijn gedurende de laatste tien jaar de nicuwe conglomerates hun oudere equivalenten, de 'diversified majors' voorbijgestreefd. De term 'conglomerate' wordt hier gebruikt voor een bedrijf dat zeer snel gediversifieerd is door een serie van overnames en fusies in niet verwante gebieden (Gulf and Western, ITT). De term 'diversified majors' wordt gebruikt voor een bedrijf dat gedurende cen lange periode hoofdzakelijk door interne groei in aanverwante sektoren is vergroot (General Electric).

De conglomerates lijken in omvang, produktassortiment en formele organisatiestruktuur op de 'diversified majors'. Het nieuwe van conglomerates is de snelheid waarmee zij hun diversificatie hebben bereikt.

De benadering van het management bij conglomerates is zeer verschillend van die der andere catc. gorie. De rol van het topmanagement ten opzichte van de divisies is cen sleutelkwestie voor elke gediversifieerd bedrijf. De conglomerates hebben cen kleine staf - meer gericht op algemene zakelijke bekwaamheden - in plaats van grote groepen specialisten in het hoofdkantoor die diensten verlenen aan en de politiek ontwikkelen voor de divisies. Zij letten er meer op dat de divisies goed geleid worden dan dat zij aan dat management zelf deelnemen. Zij zullen de afzonderlijke eenheden beter leiden dan de 'majors' maar ten aanzien van de voordelen op het gebied van centrale research, interne samenwerking en coördinatie tussen de divisies bezitten de laatsten voordelen. De conglomerates en de 'diversified majors' kunnen nog veel van elkaar leren.

B VI-16

E 641.22

Harvard Business Revien', november/december 1969

\section{LEER VAN DE ARBEIDSVOORWAARDEN}

\section{Ontwikkelingen in en rondom de sociale verzekering}

Rietkerk, J. G. - Het peil van sociale voorzieningen in ons land was in het begin van de zestiger jaren in vergelijking met andere Westeuropese landen lang niet het hoogst. In 1965 was die achterstand voor een bclangrijk deel ingehaald. Het vermoeden bestaat, dat deze snelle groei ook na 1965 is voortgezet. Met verdere sterke uitbreiding van de sociale verzekeringen dient men voorzichtig te zijn, in die zin dat 
men tot programmering van noodzakelijke verbetcringen moet komen, en prioriteitenschema's cn doorvoering a thankelijk moet stellen van sociale en economische mogelijkheden.

Socialc verzekering is een middel om degenen, die buiten hun wil nict of gedecltelijk in staat zijn in hun levensonderhoud te voorzicn, te steunen. De voorzieningen dienen zich tot het noodzakelijke te beperken; aan de eigen verantwoordelijkheid van de burger voor zijn bestaan mag geen afbreuk worden gedaan. Dit om onnodig profiteren van de socialc voorzicningen te vermijden en tevens te voorkomen dat de financiële mogelijkheden voor meer urgente veranderingen in het gedrang zouden komen.

Het huidige pakket van sociale verzekeringen vergt aan uitkeringen een bedrag, dat gelijk is aan de helft van de Rijksbegroting. Een aantal verbeteringen is wenselijk: op drieërlei gebied komen nog belangrijke witte plekken, t.w. dat van de pensioenvoorzieningen, de invaliditeitsvoorziening en van de ziekenfondsverzekering.

Naast de wensen tot verbetering zijn er ook wensen tot het aanbrengen van beperkingen: ten aanzien van kinderbijslagen, herinvocring carenzdagen en van invoering van een eigen risico in de ziekenfondsverzekering. Met betrekking tot de financiering van de sociale verzekering is - in vergelijking met andere landen - het aandeel van de overheid in de kosten gering. Opvoering van dit aandecl zal ten koste gaan van andere voorzieningen.

Ook voor premieverhoging zijn de mogelijkheden in de toekomst nict groot. Daarom is programmering zo belangrijk.

Met betrekking tot de sociale voorzieningen, die door de overheid uit de algemene middelen worden gefinancierd, lijkt grondige bestudering van de gedachte van de negatieve inkomstenbelasting aanbevelenswaardig.

Ba VII 9

Sociaal Maundblad Arbeid, december 1969

E 260

\section{Ontwikkelingstendenzen van de sociale verzekering}

Berends, H. - In dit artikel worden enkele beschouwingen gegeven over: 1. uitbreiding der sociale verzekering 2. premiedruk en uitgavenniveau der sociale verzekering 3. is programmering der sociale verzckering noodzakelijk? 4. financiering der sociale verzekering en 5 . kostenbewaking in de sociale verzekering.

Over uitbrciding van sociale verzekering wordt gezegd, dat hieraan niet is te ontkomen aangezien grote groepen in onze samenleving relatief nog weinig van de welvaart profiteren.

De premiedruk blijkt in Nederland in vergelijking met een viertal E.E.G.Ianden (België, Italië, Duitsland, Frankrijk), het hoogst te zijn. Oorzaak is de afwijkende wijze van financiering. Wat betreft het uitgavenniveau blijken zich tussen genoemde landen geen extreme verschillen voor te doen.

Programmering van de collectieve voorziening, waronder de sociale verzekeringen, is economisch noodzak elijk.

Is programmering van de sociale verzekering mogelijk door normering van premiedruk en uitgavennivcau? Binding van de premiedruk aan een vast percentage lijkt welhaast niet mogelijk. Toch moet een zekere begrenzing doorgevoerd worden. Voor de werknemers is die te vinden. Aangegeven is dan echter nog niet hoe de verdeling over verschillende scktoren der collectieve voorzieningen moet geschieden. Dit laatste is afhankelijk van de op wat langer termijn gestelde economische en sociale doelstellingen.

De financicring van de sociale verzekering dient ook wijzigingen te ondergaan. De overheidsbijdrage is onvoldoende, waardoor de premiedruk te zwaar wordt. Wat de economische gevolgen zijn van een gedeeltelijke overgang van premieheffing naar belastingheffing is moeilijk te zeggen. Dient de heffingsgrondslag van de sociale verzekering, t.w. het verzekeringsplichtig inkomen niet te worden gewijzigd? Geweren is reeds door anderen o.m. in Duitsland, op de toegevoegde waarde als grondslag.

In de discussie over kostenbeperking in de sociale verzekering gaat het vooral om de toepassing van Ziekenfondswet en Ziektewet. De mogelijkheid van overdracht van „eigen risico" aan ziekenfondsen of andere verzekeraars en het ziekteverzuim van werknemers zijn aspekten, die in dit verband nader bestudecrd dienen te worden.

Ba VII -9

Sociaal Maandblad Arbeid, december 1969

E 260 